\title{
Self-Stigma Experiences Among Older Adults with Mental Health Problems Residing in Long-Term Care Facilities: A Qualitative Study
}

\author{
Vasiliki Tzouvara, $\mathrm{PhD}^{\mathrm{a}}$, Chris Papadopoulos, $\mathrm{PhD}^{\mathrm{b}}$, and Gurch Randhawa, $\mathrm{PhD}^{\mathrm{b}}$

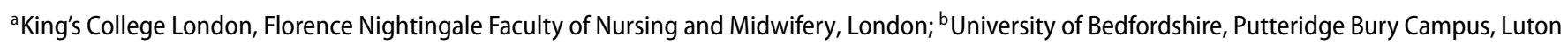

\begin{abstract}
Self-stigma is linked with a variety of deleterious consequences for the stigmatised individual. Much of the past research on self-stigma focuses on younger adults; however, little is known about the self-stigma experience among institutionalised older adults with mental health problems. This study aims to explore experiences of self-stigma among older adults with mental health problems in long-term care facilities. Ten semi-structured interviews were conducted. Insight into mental illness was identified as having a key influence upon the self-stigma experiences among this group. Participants shared common understandings, views, and behavioural reactions towards mental health problems. Lacking control, public stigma, sympathy, disinterest, avoidance, and fear were key themes among them. Re-conceptualising self-stigma theories and implementing interventions that aim at reducing stigmatising attitudes among this group are essential.
\end{abstract}

\section{Introduction}

Mental illness self-stigma can be defined as the internalisation process of negative public stereotypes to oneself (Ritsher, Otilingam, \& Grajales, 2003), and may be characterised 5 by shame, secrecy, discrimination, and social withdrawal (Goffman, 1968). Much of the past research on self-stigma has focused on older adults suffering from schizophrenia (Loch et al., 2013), bipolar disorder (Howland, Levin, Bixen, Tatsuoka, \& Sajatov, 2016), post-traumatic stress disorder (Mittal et al., 2013; Pless Kaiser, Seligowski, Spiro III, \& Chopra, 2016) and those receiving outpatient mental health services (Boyd, Juanamarga, \& Hashemi, 2015). These and other studies have shown that self-stigma is linked with a variety of deleterious consequences for the stigmatised individual such as unemployment, income loss, lower self-esteem, self-efficacy, empowerment, and poorer treatment-seeking behaviour (Britt, Jennings, Cheung, Pury, \& Zinzow, 2015; Brohan, Elgie, Sartorius, Thornicroft, \& GAMIAN-Europe Study Group, 2010; Brown et al., 2010; Corrigan, Watson, \& Barr, 2006; Pokrajac, Nolimal, \& Leskovsek, 2016; Wade et al., 2015).

Much less is known about the self-stigma experience among older adults with mental health problems. Werner, Aviv, and Barak (2008) reported that among 86 older and younger inpatients with schizophrenia, moderate levels of self-stigma $33 \%$ of them experienced high levels of self-stigma. Werner, Stein-Shvachman, and Heinik (2009) also identified moderate levels of self-stigma among 54 Israeli older adults experiencing depression. Griffiths (2008) investigated self-stigma and its

30 association with treatment adherence among 14 U.K.-based older adults with mental illness using out-patient mental health services (age range $=65-92$ years). They identified low levels of self-stigma which did not significantly impair participants' willingness to continue using mental health care services. Conner, McKinnon, Ward, Reynolds, and Brown (2015) using a mixed-methods approach investigated whether and how peer education interventions improve attitudes and minimise self-stigma among 19 U.S.-based older adults (aged 60 years or above) suffering from depression. Pre-intervention data showed that both perceived public stigma and self-stigma were reported at moderate-high proportions among this age group. Older adults argued that their cohort age was happy to openly discuss physical problems, yet they were reluctant to discuss problems related to their mental health well-being and to talk to mental health professionals. Older adults believed that seeking treatment would further increase stigma experiences.

In the current study we aimed to contribute to the evidence base associated with the self-stigma experience among older adults with mental health problems by investigating this phenomenon within the long-term care home setting, a setting that has previously been over-looked in this domain of research. This is despite evidence that older adults residing in long-term care facilities often experience mental health problems. This was evidenced by Seitz, Purandare, and Conn's (2010) systematic review of mental illness prevalence among long-term care residents. Specifically, the study highlighted that the median prevalence of major depressive disorder was $10 \%$, while the median prevalence of depressive symptoms was $29 \%$ in this population. A cross-sectional study of older adults residing in six U.K.-based nursing homes revealed that $59.6 \%$ of them had a medical record of mental illness and almost half of them suffered from depressive, anxious or sad $\operatorname{mood}(n=151,43.1 \%$, DRS $=$ 
$\geq 3$, mean $3.8 \pm 4.8$ ) (Tzouvara, 2016). The above findings are in line with estimations by Age UK (2017) that $40 \%$ of older people in care homes suffer from depression. This population is therefore exposed to other people with mental health problems, and their experience of institutionalisation which may also impact upon their self-esteem (Chiang, Lu, Chu, Chang, \& Chou, 2008; Kostka, \& Jachimowicz, 2010), increasing the likelihood of agreement with the negative stereotypes associated with mental

70 illness. The principles of awareness and agreement of stereotypes represents a central feature of the self-stigmatisation process according to Watson, River, and Corrigan's (2005) socio-cognitive model. This model proposes that if awareness and agreement of stereotypes and public stigma does occur, uations may occur, resulting in self-stigma. The socio-cognitive model also highlights the likely negative outcomes of self-stigma including reducing self-esteem, self-efficacy, and the "why try?" effect. This refers to reluctance and reduced motivation towards 80 achieving personal goals, increasing the risk of concealment and withdrawal from social relations and services that may benefit people with mental health problems.

\section{Data and methods}

A qualitative descriptive approach was adopted. Sandelowski 85 (2000, p. 336) states that "qualitative descriptive studies offer a comprehensive summary of an event in the everyday terms of those events" while "researchers conducting such studies seek an accurate accounting of the meanings participants attributed to those events." This approach therefore enabled us to compre90 hensively understand the meanings older adults attach to their experiences during their time residing in nursing homes.

The interview schedule included questions that aimed to tap into lived experiences of stigma. The opening question was, "Could you please tell me a bit about your life before coming 95 in the nursing home? This question aimed to ease participants into the interview. Subsequent questions aimed to investigate the potential experiences of self-stigma including the roles of cognitive, personal, and socio-cultural phenomena. The interviews, conducted by \#\#, lasted between 30 minutes and 1 hour and took place in a quiet, neutral room in the nursing homes.

\section{Sample}

The participant eligibility criteria were English-speaking older adults aged 60 years and above, without severe cognitive impairment, suffering from mental health problems, and residing in an eligible nursing home. Cognitive ability and psychological well-being of older adults were assessed using the interRaiLong-Term Care Facilities (interRai-LTCF) tool. This tool consists of several outcome measures: the Cognitive Performance Scale (CPS) that measures cognitive ability (CPS $=\leq 3$ ), that assess psychological well-being (DRS $=\geq 3$, AHS $=\geq 3$ ), and the Aggressive Behaviour Scale that measures aggressive behaviour ( $\mathrm{ABS}=\geq 3$ ) were utilised as a proxy of mental illness. The tool is reliable (Hirdes et al., 2008), and has been previously used in assessing and comparing older adults' characteristics in health care settings (Heckman et al., 2013). The screening assessments were completed by nursing home staff as per the screening tool's instructions. All older adults who were residing in one of the six nursing homes who passed initial screening $(n=14)$ were then approached by nursing home staff and were asked if they wished to talk to the researcher. Residents who expressed an interest were then given a participant information sheet and informed consent form. The researcher spent as much time as it was necessary in order to explain the study and answer any questions. This procedure resulted in the recruitment of ten participants (two eligible people died during recruitment, one was transferred to a hospital and one refused to participate in the interviews). Data collection and analysis occurred for a period of two months. Ethical approval was obtained by the University of Bedfordshire's Institute for Health Research Ethics Committee.

\section{Setting}

Six nursing homes were recruited (for a detailed discussion of recruitment methods and challenges, please see Tzouvara, Papadopoulos, and Radhawa (2016)). Eligible nursing homes were operating in the county of Bedfordshire, and needed to formally provide mental health services to their residents. All participating nursing homes were privately owned with four provided specialised care to older adults.

\section{Analysis}

Content analysis was performed because this method is in line with a qualitative descriptive study (Sandelowski, 2000). The research team read the transcripts several times to become familiar with the content of the transcripts. This method provided an initial understanding of the interviews. Codes were systematically applied, but they were also generated from the data themselves. After coding the data, the research team merged the codes into several themes and sub-themes, and explanations were sought on whether and how older adults experienced self-stigma. Qualitative content analysis is reflexive and interactive because researchers constantly modify the data to fit in new data and new insights in relation to the data (Sandelowski, 2000). This method led to the development of further sub-themes that identified potential links between the emerged themes and the socio-cognitive self-stigma model. The analysis was performed using the software package, "NVivo10." In eliminating bias and personal preferences (so that to improve credibility) the research team used the methods of "debriefing" and "prolonged engagement" (Shenton, 2004). Debriefing sessions were held among the research team and helped to identify researchers' biases, eliminate them, re-think emerged themes, and adjust where it was necessary for the best interpretation of the findings. Prolonged engagement with participants' environment was achieved during a previous quantitative phase of this study. The phase involved a questionnaire survey and aimed to examine the interrelationships between loneliness, self-stigma, and culture among older adults with mental health problems in long-term care facilities (Tzouvara, 2016). The first researcher visited participants' environment many times before the commencement of the qualitative phase. Early engagement resulted in a clear understanding of what would be expected during the 
Table 1. Respondents' socio-demographic characteristics.

\begin{tabular}{llclc}
\hline Pseudonymous & Gender & Age Range & Marital Status & Cultural Background \\
\hline Hope & Female & $60-70$ & Single & English \\
Janet & Female & $60-70$ & Married & English \\
Rose & Female & $60-70$ & Widowed & English \\
Silvia & Female & $70-80$ & Widowed & English \\
Janis & Female & $80-90$ & Divorced & English \\
Kieran & Male & $60-70$ & Single & English \\
George & Male & $60-70$ & Single & English \\
John & Male & $70-80$ & Married & English \\
David & Male & $80-90$ & Widowed & English \\
lan & Male & $90-100$ & Widowed & English \\
\hline
\end{tabular}

implementation of the study, as well as to the establishment of familiarity and relationships of trust.

\section{Findings}

175 Ten older adults from six nursing homes in Bedfordshire were interviewed. The age range of respondents was 60-100 years. Five respondents were male, and five female. The majority of the respondents were widowed, while one respondent was divorced. All respondents identified themselves as white-English. The

180 names of the respondents used below are pseudonymous, and age range instead of actual age was used in maximising anonymity (Table 1).

The analysis of the interviews revealed that insight into mental illness had a meaningful influence upon the experiences of self-stigma among this population. Insight was viewed as "a person's capacity to understand the nature, significance, and severity of his or her own illness" (Reddy, 2015, p. 257). Older adults with an insight into their illness experienced self-stigma through rejection, isolation, and inferiority. On the other hand,

190 older adults who had no or little insight into their illness did not appear to experience self-stigma. Reddy (2015, p. 258) argues that patients with good insight into their illness are more likely to a "carrying the load of stigma" and, as a result, the risk of depression and suicidal ideation is increased. Evidence of this was relationship was identified by Vidović, Brecić, Vilibić, and Jukić (2016) whose cross-sectional study revealed a significant positive correlation between insight and self-stigma among patients with schizophrenia. Therefore older adults who have a greater understanding of their mental health problems might be more vulnerable to self-stigmatisation because they are aware of the public's negative attitudes towards their condition. This may cause feelings of rejection, inferiority, and isolation among them. The analysis also revealed that participants hold similar attitudes and understandings towards mental illness regardless of whether they possessed an insight into their own condition. 205 Participant's views, perceptions, and behavioural reactions towards peers with mental health problems demonstrated the existence of stigmatising attitudes among this group. All the themes and sub-themes are presented in Table 2.

\section{Insight into mental illness and experiences of self-stigma}

Participants living in a nursing home that specialised in mental health care provision were found to be particularly aware of their condition. These participants self-stigmatise themselves through feelings of rejection and inferiority. For example, one participant states:

\begin{abstract}
"... When I used to go down years ago and knock on the door she (her sister) sent me away. I get a taxi and go down she says off you go you ain't coming in here you know. It was like that with me. She treated me as if I couldn't have anything to do with her and her family cause I was psychiatric or something. She held it against me. Made me feel rejected really." (Hope).
\end{abstract}

"Inferior. I mean I was considered myself a patient you know. I had to go there as a patient. There was staff that was superior to me." (Hope).

Self-stigma was also identified within participants' accounts 225 of isolation. More specifically, participants revealed a strong reluctance to communicate and interact with other residents, and/or people in the community because of their own mental health problems. This is illustrated in the following interview excerpts:

\footnotetext{
"They don't talk to me (staff and other residents). They don't make any conversation with me. They don't know me. Why should I bother? ... See, I don't see many people, I don't get many people to speak to. So I don't know what impression I make really. I really don't know ... I am glad you came cause I am an isolated person" (Hope).
}

Table 2. Themes, sub-themes and sample of participants' quotes.

\begin{tabular}{|c|c|c|}
\hline Main Themes & Key Sub-Themes & Sample of Participants' Quotes \\
\hline $\begin{array}{l}\text { 1. Insight into mental } \\
\text { illness and experiences } \\
\text { of self-stigma }\end{array}$ & - & $\begin{array}{l}\text { ". . When I used to go down years ago and knock on the door she (her sister) sent me away... She } \\
\text { treated me as if I couldn't have anything to do with her and her family cause I was psychiatric or } \\
\text { something. She held it against me. Made me feel rejected really." } \\
\text { "I keep it secret, because there is a bit of stigma attached to it. But they are a lot of them who are the } \\
\text { same as me. We never discuss our illness in front of other people, no, no." } \\
\text { "Inferior. I mean I was considered myself a patient you know. I had to go there as a patient. There was } \\
\text { staff that was superior to me." }\end{array}$ \\
\hline $\begin{array}{l}\text { 2. Understanding and } \\
\text { views towards mental } \\
\text { illness: }\end{array}$ & a) Lacking control & $\begin{array}{l}\text { "It's not many of them. Just the few of the men. Because they get out of control. They hit and they got } \\
\text { knifes up and things. Yes, they do" }\end{array}$ \\
\hline 2a. Perceptions & b) Public stigma & $\begin{array}{l}\text { "You are the lowest type unless you do something for yourself jobs and things, try to go to work and } \\
\text { support yourself and you know develop some friends around you and get interests. People would } \\
\text { hold back from you..." }\end{array}$ \\
\hline \multirow[t]{2}{*}{ 2b. Attitudes } & a) Sympathy & "We are in the same boat as them." \\
\hline & b) Disinterest & $\begin{array}{l}\text { "I don't worry about them miss. They don't worry about me, why should I worry about them? Everybody } \\
\text { here should have a family." }\end{array}$ \\
\hline \multirow[t]{2}{*}{ 3. Behavioural Reactions } & a) Avoidance & "I don't mix with anybody here" \\
\hline & b) Fear & $\begin{array}{l}\text { "Well I'm frightened of them enough. I've been never been hurt so far but I'm frightened of them over } \\
\text { the meals... Because they get out of control ... }\end{array}$ \\
\hline
\end{tabular}


"I was quite a bubbling person, chatting, I got depressed and didn't want to go out. I just stayed in bed, stayed in the house" (Janet).

In addition, participants were found to experience selfstigma through their need for secrecy and concealment of their condition because of the negative perceptions and stereotypes associated with mental illness. For example, one participant states:

"I keep it secret, because there is a bit of stigma attached to it. But they are a lot of them who are the same as me. We never discuss our illness in front of other people, no, no" (George).

Participants were generally reluctant to identify themselves as people suffering from mental illness. The majority expressed negative reactions towards the possibility of having mental health problems themselves. In some instances, when partici250 pants were asked to state their opinion about mental illness, their immediate reaction was to clarify that they did not suffer from the illness. For example:

"No thank God. Well I've never been told I have mental illness"(Janis).

However when participants were assured that the interviewer was not implying that they were experiencing mental health problems, they were more willing to start a conversation about it and express their views on the matter.

\section{Understanding and views towards mental illness}

Participants were found to share the same understanding and

views towards mental health problems. Three main sub-themes emerged: perceptions, attitudes, and behavioural reactions.

\section{Theme 1: Perceptions}

In relation to perceptions, three sub-themes emerged: "lacking control," "distraction," and "public stigma."

\section{Lacking control}

Participants perceived people with mental illness as aggressive, violent, and lacking control. Many participants talked about incidents of violence from other residents who they believed were suffering from mental illness.

\section{Public stigma}

Some participants talked about the negative views that the public holds towards people with mental illness, including 285 the embarrassment they may cause for the community. For example:

"You are the lowest type unless you do something for yourself jobs and things, try to go to work and support yourself and you know develop some friends around you and get interests. People would hold back from you. if there is a rumour or something 'oh you are a patient, she is a patient'; she is a social embarrassment in the community or something" (Hope).

There was also an understanding among some participants that the stigma towards mental illness can develop from people's misconceptions and poor understanding about it:

"Well, there is a bit of a stigma attached to in the outside community. Yeah. Cause, they probably can't understand what is about really... Well some people when they know that someone gots mental illness, they perhaps try to avoid them. Scared that they might get violent or something, yeah" (George).

\section{Theme 2: Attitudes}

In relation to attitudes, two sub-themes emerged: sympathy and disinterest.

\section{Sympathy}

Sympathy was a prominent aspect of older adults' attitudes towards people with mental illness. The majority of the participants seemed to sympathise with those who experience mental illness because "they didn't choose it," or because "they are in the same boat as them."

\section{Disinterest}

Some older adults revealed a disinterest about the problems that people with mental illness might be dealing with, instead suggesting that the onus is upon families to show support. An example of this comes from John who states:

"I don't worry about them miss. They don't worry about me, why should I worry about them? Everybody here should have a family."

\section{Theme 3: Behavioural reactions}

Negative reported behavioural reactions were identified throughout the interviews. Two sub-themes emerged: avoidance 320 and fear.

\section{Avoidance}

Participants preferred to keep their distance from older adults who they believed were experiencing mental health problems. Many participants stated that they were unwilling to ever inter- 325 act with such people, and stated that just being in the same room
"I can't stand the noise during meal times, sometimes I just hurry up and go upstairs, take the tracks and go upstairs by myself... I do talk to the residents that are friendly and quite controlled" (Hope). 
with those perceived to be experiencing mental health problems was upsetting and at times scary because of their perceived uncontrollability:

"They used to upset me, so I didn't bother to go anymore in there (activities room) ... sometimes some other ladies used to shout and scream and they cannot help themselves and the staff got them out of the room sort of thing" (Silvia).

"I don't mix with anybody here" (John).

"No I've never got involved with any of them really, you know, to talk to. John he gets all psychotic and threatens people... Problems with him, you know" (Hope).

Some participants also argued that other residents preferred to isolate themselves in their rooms. For example:

"They usually are in their place, their own. They don't mix, no no they don't" (Ian).

"He is very changeable you know. I think it's his mood. He shits there for hours on his own. He doesn't relate to anybody" (Hope).

\section{Fear}

Two participants disclosed feelings of fear towards other residents due to their perceived uncontrollability and potential of violence and aggression. This is illustrated by two residents residing in a mental health specialised nursing homes:

"Frightened, yeah, because the lady threw the table at me once... and all the shouting that's going on ... when I'm frightened I go the corner and cry, I've got my emotions, I cry very often" (Janet).

"Well I'm frightened of them enough. I've been never been hurt so far but I'm frightened of them over the meals. I want to rush out, you know, run out to town. It's just the reaction to it. It's not many of them now. Just the few of the men. Because they get out of control. They hit and they got knives and things. Yes they do" (Hope).

\section{Discussion}

Having an insight into one's mental illness was found to have a particularly meaningful role in how participants experience self-stigma. Older adults with insight experienced self-stigma through feelings of inferiority, rejection, and isolation. Previous research has highlighted that personal insight is associated with illness severity and poor treatment compliance (Beck, Cavelti, Kvrgic, Kleim, \& Vauth, 2011; Lincoln, Lullmann, \& Rief, 2007), poor clinical outcomes (Drake et al., 2007; Saravanan et al., 2010), reduced long-term global functioning (Lincoln et al., 2007), higher levels of depressive symptoms (Murri et al., 2015), and higher stigma. For example, Mishra, Alreja, Sengar, and Singh's (2009) cross-sectional study among 100 psychiatric

370 patients (in-patient and out-patient services) found that levels of stigma were higher among those participants who had insight into their illness. The study participants also highlighted that misconceptions about mental health problems trigger public stigma to occur. Awareness of mental illness public stigma might cause and/or intensify experiences of self-stigma among this population. This could result in a reduced ability for this population to cope with their illness and formulate social relationships.

Goffman (1968), who studied the impact of institutionalisation on people with mental illness, conceptualised self-stigma as: "internalised feelings of guilt, shame, inferiority and wish 380 for secrecy experienced by those who live with mental illness." Similar themes were identified in the current study with those experiencing self-stigma reporting feelings of inferiority, reluctance for social interaction (withdrawal), and avoidance towards self-identifying themselves as suffering from mental health problems (shame and secrecy). Feelings of inferiority, alienation, and shame have been previously reported in the self-stigma literature (Girma et al., 2013).

Sympathy was perhaps the predominant feeling among this study's population towards peers with mental health problems; yet, despite this, participants were largely disinterested in the difficulties that their peers may be facing. It could be argued that this aligns with Watson et al.s (2005) socio-cognitive model to self-stigma. Firstly, it might be argued that their disinterest in supporting peers, despite their feelings of sympathy, reflects the "why try" phenomenon. Second, this could be viewed as a type of withdrawing from social relations, perhaps in part an attempt to conceal their own difficulties to their peers. Less debatable is the interpretation that this reflects a disconnection of social relationships between residents. Indeed, participants' unwillingness to socially interact with older adults experiencing mental illness emerged as a key theme to emerge in our analysis. In addition to the "why try" effect and the potential desire to conceal one's own mental health difficulties, this may be due to the fear residents hold towards their peers, a fear rooted in the stigmatising perceptions of potential violence and uncontrollability (Economou et al., 2012; Kodakandla, Nasirabadi, \& Pasha, 2016). Such perceptions were also identified within the analysis, with residents' viewing their peers as being violent and uncontrollable. Perceiving people with mental health problems as violent and out of control is a common attribution from the general public. For example, a 2006 national survey found that $60 \%$ and $32 \%$ of Americans believed that people with schizophrenia and major depression, respectively, were likely to act violently towards others (Harvard Health Publications, 2011). It is worth mentioning, however, that this public perception does not reflect reality and analyses in a number of high income countries suggest that the risks of violence by someone with mental health problems are no greater than those for the general population as a whole (McDaid, 2005). One possible explanation for why older adults stigmatise their peers could be that this population lacks mental health literacy and awareness. In addition, this population is more likely to witness mental health crises and/or acute episodes of mental illness in a daily basis that could explain stigmatising attitudes among them. Nursing homes therefore need to find ways of creating an atmosphere of belonging, sharing, and compassion of others' wellbeing so to boost social relationships and reduce loneliness. In doing this, older adults are likely to be in a better position to understand their peers and challenge stigmatising attitudes they may hold towards them. Future research could look at the impact of staff and family attitudes on this population, their opportunities for socialisation, and their ability to function as integrated members of the society.

Overall, the analysis of this study identified self-stigma experiences among older adults suffering from mental health problems in long-term care facilities. Although there are a number of anti-stigma campaigns, they mainly aim to reduce public stigma. An example of this is the U.K.'s national “Time to

\section{0}


Change" campaign that aimed at challenging the public stigma 440 associated with mental illness and succeeded in overall improvement in attitudes towards mental illness (Time to Change, 2015). However, there have been no large scale campaign to tackle mental illness self-stigma, including across the life span. In addition, the issue fails to receive the attention it deserves with 445 the majority of the existing policies and strategies for older adults' mental care provision to often address to specific mental health problems (e.g. The National Dementia Strategy, 2009; Dementia Challenge (Department of Health, 2012)) which compounds the problem of mental illness self-stigma.

The need of anti-stigma interventions targeting this population is therefore urgent. For example, there is currently an abundance of compelling evidence that interventions with psycho-educational mechanisms as a key mechanism of action can be effective in improving a range of outcomes, including, 455 for example, mental illness public stigma, courtesy stigma, and self-stigma (Mittal et al., 2013; Yanos, Lucksted, Draoalski, Roe, \& Lysarek, 2015), resulting in improved functioning and quality of life, decreased symptomatology, and positive outcomes for both a person experiencing mental illness and the family members (Lukens \& McFarlane, 2004). There is also evidence that mental illness self-stigma interventions that integrate cognitive re-structuring strategies can further augment effectiveness (Lucksted et al., 2011), as can "narrative enhancement" strategies (Yanos, Roe, \& Lysaker, 2011). The latter may

465 be particularly useful for long-term care home settings since it enables in-depth discussions about personal experiences, narratives, and reflections about themselves, thus promoting social connectedness. Social connectedness, community re-integration, and a sense of belonging have been recently 470 evidenced to be potentially key in protecting against self-stigma (Treichler \& Lucksted, 2017). Future research that learns from these strategies and attempts to translate and modify these interventions into older adult care home settings would be invaluable.

475 Interventions that reduce mental health stigma by professional staff will also be beneficial given how key staff are in the provision of care and resident's overall wellbeing, and because being exposed to stigma is key to self-stigma occurring. Mårtensson, Jacobsson, and Engström (2014), after examining

480 mental health nursing staff's attitudes towards mental illness, concluded that positive attitudes among staff towards people with mental illness could be developed and transmitted in the subculture at work places by employers/workplaces. Horsfall, Cleary, and Hunt (2010) argue that while staff will benefit from interventions that increase mental health literacy, involving them in supervision and processes that actively highlight and challenge their own beliefs and attitudes could also be key. This, however, will have to be carefully balanced (and perhaps integrated) with reflection upon how nurses combat the asso-

490 ciative stigma they are vulnerable to experiencing by the public (Flaskerud, 2017). Ihalainen-Tamlander, Vähäniemi, Löyttyniemi, Suominen, and Välimäki’s (2016) survey of Finnish nursing staff $(n=264)$ revealed that stigmatising attitudes towards people with mental health problems are particularly 495 prevalent among younger nurses or those without additional mental health training. They concluded that both nursing education and on-the-job training would be key towards preventing younger nurses from developing stigmatised attitudes during their careers. The importance of an early educational intervention is supported by Bingham and O'Brien (2017), who were able to show that employing guided clinical experience as an educational intervention among first year undergraduate nursing students can foster positive change in nurse's attitudes and reduce stigma. Bilge and Palabiyik (2017) were also able to demonstrate that improving nursing students is possible by co-producing short films about mental health disorders.

Interventions such as these are of crucial importance since staff who possess compassionate and positive attitudes towards those experiencing mental illness are more likely to provide higher quality care (Fokuo et al., 2017; Suwalska, Suwalska, Neumann-Podczaska, \& Łojko, 2017). It is also important that any intervention designed to be applied in such settings hold a long-lasting effect (Mehta et al., 2015) and benefit from the perspectives and insights into those who it is aiming to serve. Therefore, it is of crucial importance that interventions are designed with relevant stake-holders, including older adults, families, and care staff. The promotion of person-centered and recoveryorientated relationships between older people and mental health and psychiatric nursing staff is also key (Lesser \& Paleo, 2016). However, stigma's ubiquitous reach serves to threaten both of these types of relationships, since it can jeopardise patient morale and spirit, crucial in the recovery process (Onken, Craig, Ridgway, Ralph, \& Cook, 2007), and bring entrenched stereotypes into interactions with patients that lead to assumptions and a reduced view of the patient (Delaney, 2012). Nurses should be made aware of these issues so that they can challenge and address the impact of stigma on the compassionate, patientcentered care patients need.

Saturation on the main themes was achieved, however due to sample size challenges sub-themes in relation to self-stigma were not saturated. This is a key limitation; however it could not have been further addressed since the authors interviewed all the participants who were available to them and met the eligibility criteria. Geographical variations have not been explored which is another limitation of this study. However, adequate inferences can be made in relation to understandings, views, and behavioural reactions towards mental illness among this population. In addition, it was not known to the research team if the eligible participants in the current study had a formal 540 diagnosis of a mental health problem. While psychological well-being was assessed in the current study, our screening tool is not a diagnostic tool.

\section{Conclusion}

In conclusion, this study identified insight into illness as play- 545 ing a potentially important role upon self-stigma experiences among older adults with mental health problems in long-term care facilities. Further research is required to confirm this observation. However, if true, it is important to reflect upon current theoretical approaches, and to potentially re-conceptualise self- 550 stigma in order to integrate the important role of insight. Public and self-stigma were both identified in this population and

. 
were manifested through fear, reluctance for social interaction, shame, secrecy, and withdrawal. Interventions that reduce the likelihood of self-stigma occurring and/or minimise or reverse its damage to wellbeing are required for this population and setting.

\section{Acknowledgments}

The authors would like to thank the participants of this study.

\section{Declaration of interest}

The authors report no conflicts of interest.

\section{References}

Age UK. (2017). Later life in the United Kingdom. Retrieved from: https:// www.ageuk.org.uk/Documents/ENGB/Factsheets/Later_Life_UK_ factsheet.pdf?dtrk=true

Angermeyer, M. C., Matschinger, H., \& Schomerus, G. (2013). Attitudes towards psychiatric treatment and people with mental illness: Changes over two decades. The British Journal of Psychiatry, 203, 146-151. doi:10.1192/bjp.bp.112.122978.

Beck, E. M., Cavelti, M., Kvrgic, S., Kleim, B., \& Vauth, R. (2011). Are we addressing the 'right stuff' to enhance adherence in schizophrenia? Schizophrenia Research, 132, 42-49.

Bilge, A., \& Palabiyik, O. (2017). The effect of short films about mental health and disorders on preventing stigmatization in nursing education. Archives of Psychiatric Nursing, 31, 88-92.

Bingham, H., \& O'Brien, A. J. (2017). Educational intervention to decrease stigmatizing attitudes of undergraduate nurses towards people with mental illness. International Journal of Mental Health Nursing, 1-9.

Boyd, J. E., Juanamarga, J., \& Hashemi, P. (2015). Stigma of taking psychiatric medications among psychiatric outpatient veterans. Psychiatric Rehabilitation Journal, 38, 132-134. doi:10.1037/prj0000122.

Britt, T. W., Jennings, K. S., Cheung, J. H., Pury, C. L. S., \& Zinzow, H. M. (2015). The role of different stigma perceptions in treatment seeking and dropout among active duty military personnel. Psychiatric Rehabilitation Journal, 38, 142-149. doi:10.1037/prj0000120.

Brohan, E., Elgie, R., Sartorius, N., \& Thornicroft, G. \& GAMIANEurope Study Group (2010). Self-stigma, empowerment and perceived discrimination among people with schizophrenia in 14 European countries: The GAMIAN-Europe study. Schizophrenia Research, 122, 232-238.

590 Brown, C., Conner, K. O., Carr Copeland, V., Grote, N., Beach, S., Battista, D., \& Reynolds, C. F. III (2010). Depression stigma, race, and treatment seeking behaviour and attitudes. Journal of Community Psychology, 38, 350-368. doi:10.1002/jcop.20368.

Chiang, K. J., Lu, R. B., Chu, H., Chang, Y. C., \& Chou, K. R. (2008). Evaluation of the effect of a life review group program on self-esteem and life satisfaction in the elderly. International Journal of Geriatric Psychiatry, 23, 7-10. doi:10.1002/gps.1824.

Conner, K. O., McKinnon, S. A., Ward, C. J., Reynolds, C. I., \& Brown, C. (2015). Peer education as a strategy for reducing internalised stigma among depressed older adults. Psychiatric Rehabilitation Journal, 38, 186-193. doi:10.1037/prj0000109.

Corrigan, P. W., Watson, A. C., \& Barr, L. (2006). The self-stigma of mental illness: Implications for self-esteem and self-efficacy. Journal of Social \& Clinical Psychology, 25, 875-884.

Department of Health. (2012). Dementia challenge. Retrieved from: https://www.gov.uk/government/policies/improving-care-for-peoplewith-dementia

Drake, R. J., Dunn, G., Tarrier, N., Bentall, R. P., Haddock, G., \& Lewis, S W. (2007). Insight as a predictor of the outcome of first-episode nonaffective psychosis in a prospective cohort study in England. Journal of Clinical Psychiatry, 68, 81-86. doi:10.4088/JCP.v68n0111.
Economou, M., Louki, E., Peppou, L. E., Gramandani, C., Yotis, L., \& Stefanis, C. N. (2012). Fighting psychiatric stigma in the classroom: The impact of an educational intervention on secondary school students' attitudes to schizophrenia. International Journal of Social Psychiatry, 58, 544-551. doi:10.1177/0020764011413678.

Flaskerud, J. H. (2017). Stigma and psychiatric/mental health nursing, issues in mental health nursing. Issues in Mental Health Nursing, 1-3. Q15

Fokuo, J. K., Goldrick, V., Rossetti, J., Wahlstrom, C., Kocurek, C., Larson, J., \& Corrigan, P. (2017). Decreasing the stigma of mental illness through 620 a student-nurse mentoring program: A qualitative study. Community Mental Health Journal, 53, 257-256. doi:10.1007/s10597-016-0016-4.

Girma, E., Tesfaye, M., Froeschl, G., Moller-Leimkuhler, A., Dehning, S., \& Muller, N. (2013). Facility based cross-sectional study of selfstigma among people with mental illness: Towards patient empowerment approach. International Journal of Mental Health Systems, 7, 1-8. doi:10.1186/1752-4458-7-21.

Goffman, E. (1968). Stigma: Notes on the Management of Spoiled Identity. London: Pelican.

Griffiths, H. (2008). Self-stigmatisation and ageism amongst older people 630 accessing mental health services (Doctoral Dissertation). University of Hertfordshire, UK.

Harvard Health Publications. (2011). Mental illness and violence. Retrieved from: http://www.health.harvard.edu/newsletter_article/mentalillness-and-violence

Hauge, S., \& Kirkevold, M. (2012). Variations in older persons' descriptions of the burden of loneliness. Scandinavian Journal of Caring Sciences, 26, 553-560. Gray, L., ... Gilgen, R. (2008). Reliability of the interRAI suite of assessment instruments: A 12-country study of an integrated health information system. BMC Health Services Research, 8, 1-11. doi:10.1186/14726963-8-277.

Horsfall, J., Cleary, M., \& Hunt, G. E. (2010). Stigma in mental health: Clients and professionals. Issues in Mental Health Nursing, 31, 450-455. doi:10.3109/01612840903537167.

Howland, M., Levin, J., Bixen, C., Tatsuoka, C., \& Sajatov, M. (2016). Mixedmethods analysis of internalise stigma correlates in poorly adherent individuals with bipolar disorder. Comprehensive Psychiatry, 70, 174-180.

Ihalainen-Tamlander, N., Vähäniemi, A., Löyttyniemi, E., Suominen, T., \& Välimäki, M. (2016). Stigmatising attitudes in nurses towards people with mental illness: A cross-sectional study in primary settings in Finland. Journal of Psychiatric and Mental Health Nursing, 26, 427-437. doi:10.1111/jpm.12319.

Kodakandla, K., Nasirabadi, M., \& Pasha, M. S. (2016). Attitude of interns towards mental illness and psychiatry: A study from two medical colleges in South India. Asian Journal of Psychiatry, 22, 166-173.

Kostka, T., \& Jachimowicz, V. (2010). Relationship of quality of life to dispositional optimism, health locus of control and self-efficacy in older subjects living in different environments. Quality of Life Research, 19, 351-361. doi:10.1007/s11136-010-9601-0.

Lesser, J., \& Paleo, J. (2016). Teaching nursing students the value of personcentered, recovery-oriented relationships. Issues in Mental Health Nursing, 37, 436-439.

Lincoln, T. M., Lullmann, E., \& Rief, W. (2007). Correlates and longterm consequences of poor insight in patients with schizophrenia. A systematic review. Schizophrenia Bulletin, 33, 1324-1342. doi:10.1093/schbul/sbm002.

Loch, A. A., Guarniero, F. B., Lawson, F. L., Hengartner, M. P., Rössler, W., Gattaz, W. F., \& Wang, Y.-P. (2013). Stigma toward schizophrenia: Do all psychiatrists behave the same? Latent profile analysis of a national sample of psychiatrists in Brazil. BMC Psychiatry, 13, 2-10. doi:10.1186/1471-244X-13-92.

Lucksted, A., Drapalski, A., Calmes, C., Forbes, C., DeForge, B., \& Boyd, J. (2011). Ending self-stigma: Pilot evaluation of a new intervention to reduce internalized stigma among people with mental illnesses. Psychiatric Rehabilitation Journal, 1, 51-54.

Lukens, P. E., \& McFarlane, W. R. (2004). Psychoeducation as evidence- 680 based practice: Considerations for practice, research, and policy.
Hirdes, J. P., Ljunggren, G., Morris, J. N., Frijters, D. H. M., Finne Soveri, H., 
Brief Treatment and Crisis Intervention, 4, 205-225. doi:10.1093/brieftreatment/mhh019.

Mårtensson, G., Jacobsson, J. W., \& Engström, M. (2014). Mental health nursing staff's attitudes towards mental illness: An analysis of related factors. Journal of Psychiatric and Mental Health Nursing, 21, $782-788$.

McDaid, D. (2005). Countering the stigmatisation and discrimination of people with mental health problems in Europe. Retrieved from: http://ec.europa.eu/health/ph_determinants/life_style/mental/docs/ stigma_paper_en.pdf

Mehta, N., Clement, S., Marcus, E., Stona, A.-C., Bezborodovs, N., Evans-Lacko, S., ... Thornicroft, G. (2015). Evidence for effective interventions to reduce mental health related stigma and discrimination in the medium and long term: Systematic review. The British Journal of Psychiatry, 207, 377-384. doi:10.1192/bjp.bp.114.151944.

Mishra, D. K., Alreja, S., Sengar, K. S., \& Singh, A. (2009). Insight and its relationship with stigma in psychiatric patients. Industrial Psychiatry Journal, 18, 39-42. doi:10.4103/0972-6748.57858.

700 Mittal, D., Drummond, K. L., Blevins, D., Curran, G., Corrigan, P., \& Sullivan, G. (2013). Stigma associated with PTSD: Perceptions of treatment seeking combat veterans. Psychiatric Rehabilitation Journal, 36, 86-92. doi:10.1037/h0094976.

Murri, M. B., Respino, M., Innamorati, M., Cervetti, A., Calcagno, P., Pompili, M., ... Amore, M. (2015). Is good insight associated with depression among patients with schizophrenia? Systematic review and meta-analysis. Schizophrenia Research, 162, 234-247.

Onken, S. J., Craig, C. M., Ridgway, P., Ralph, R. O., \& Cook, J. A. (2007). An analysis of the definitions and elements of recovery: A review of the literature. Psychiatric Rehabilitation Journal, 31, 9-22.

Penner, J. L., \& McClement, S. E. (2008). Using Phenomenology to examine the experiences of family caregivers of patients with advanced head and neck cancer: Reflections of a novice researcher. International Journal of Qualitative Methods, 7, 92-101. doi:10.1177/160940690800700206.

Pless Kaiser, A., Seligowski, A., Spiro, A. III, \& Chopra, M. (2016). Health status and treatment-seeking stigma in older adults with trauma and posttraumatic stress disorder. Journal of Rehabilitation Research \& Development, 53, 391-402.

Pokrajac, T., Nolimal, D., \& Leskovsek, E. (2016). Stigma, drug addiction and treatment utilisation: PWUD perspective. Journal of Drug Abuse, 2, 28. doi:10.21767/2471-853X.100037.

Reddy, M. S. (2015). Insight and psychosis. Indian Journal of psychological Medicine, 3, 257-260. doi:10.4103/0253-7176.162909.

Ritsher, J., Otilingam, P., \& Grajales, M. (2003). Internalized stigma of mental illness: Psychometric properties of a new measure. Psychiatry Research, 121, 31-49.

Sandelowski, M. (2000). Whatever happened to qualitative description? Research in Nursing \& Health, 23, 334-340. doi:10.1002/1098240X(200008)23:4\%3c334::AID-NUR9\%3e3.0.CO;2-G.

730 Saravanan, B., Jacob, K. S., Johnson, S., Prince, M., Bhugra, D., \& David, A. S. (2010). Outcome of first-episode schizophrenia in India: Longitudinal study of effect of insight and psychopathology. The British Journal of Psychiatry, 196, 454-459. doi:10.1192/bjp.bp.109.068577.
Seitz, D., Purandare, N., \& Conn, D. (2010). Prevalence of psychiatric disorders among older adults in long-term care homes: 735 A systematic review. International Psychogeriatrics, 7, 1025-1039. doi:10.1017/S1041610210000608.

Shenton, A. K. (2004). Strategies for ensuring trustworthiness in qualitative research projects. Education for Information, 22, 63-75. doi:10.3233/EFI-2004-22201.

Suwalska, J., Suwalska, A., Neumann-Podczaska, A., \& Łojko, D. (2017). Medical students and stigma of depression. Part I. Stigmatisation of patients. Psychiatria Polska, 51, 495-502. doi:10.12740/PP/OnlineFirst/63515.

Time to Change. (2015). Our impact. Retrieved from: http://www.time-tochange.org.uk/about-us/our-impact

Treichler, E. B. H., \& Lucksted, A. A. (2017). The role of sense of belonging in self-stigma among people with serious mental illnesses. Psychiatric Rehabilitation Journal. doi:10.1037/prj0000281.

Tzouvara, V. (2016). Self-stigma, loneliness and culture among older adults with mental health problems in nursing homes (PhD Thesis). University of Bedfordshire.

Tzouvara, V., Papadopoulos, C., \& Randhawa, G. (2016). Challenges and barriers to nursing homes recruitment: Lessons learned from a small quantitative cross-sectional pilot study. Nurse Researcher, 23, 35-39. doi:10.7748/nr.23.4.35.s8.

Vidović, D., Brecić, P., Vilibić, M., \& Jukić, V. (2016). Insight and self-stigma in patients with schizophrenia. Acta Clinica Croatica, 1, 23-28.

Wade, N. G., Vogel, D. L., Armistead-Jehle, P., Meit, S. S., Heath, P. J., \& Strass, H. A. (2015). Modeling stigma, help-seeking attitudes, and intentions to seek behavioral healthcare in a clinical military sample. Psychiatric Rehabilitation Journal, 38, 135-141. doi:10.1037/prj0000131.

Watson, A. C., River, L. P., \& Corrigan, P. W. (2005). A social-cognitive model of personal responses to stigma. In P. W. Corrigan (Ed.), On the stigma of mental illness: Practical strategies for research and social change (pp. 145-164). Washington, DC, US: American Psychological Association.

Werner, P., Aviv, A., \& Barak, Y. (2008). Self-stigma, self-esteem and 770 age in persons with schizophrenia. International Psychogeriatrics, 20, 174-187. doi:10.1017/S1041610207005340.

Werner, P., Stein-Shvachman, I., \& Heinik, J. (2009). Perceptions of self-stigma and its correlates among older adults with depression: A preliminary study. International Psychogeriatrics, 21, 1180-1189. doi:10.1017/S1041610209990470.

Yanos, P. T., Lucksted, A., Drapalski, A. L., Roe, D., \& Lyserak, P. (2015). Interventions targeting mental health self-stigma: A review and comparison. Psychiatric Rehabilitation Journal, 38, 171-178. doi:10.1037/prj0000100.

Yanos, P. T., Roe, D., \& Lysaker, P. H. (2011). Narrative enhancement and cognitive therapy: A new group-based treatment for internalised stigma among persons with severe mental illness. International Journal of Group Psychotherapy, 61, 577-595. 